\title{
HUBUNGAN DUKUNGAN SUAMI DENGAN KEBERHASILAN PEMBERIAN ASI EKSKLUSIF DI WILAYAH KERJA PUSKESMAS PUSAT DAMAI KABUPATEN SANGGAU
}

\author{
RELATIONSHIP OF HUSBAND SUPPORT WITH SUCCESS OF \\ EXCLUSIVE ASI ASSOCIATION IN THE WORK AREA OF PUSAT DAMAI \\ OF SANGGAU DISTRICT
}

\author{
Yudi Agustin Saputra*, Faisal Kholid Fahdi **, Triyanan Harlia Putri *** \\ *Mahasiswi Prodi Keperawatan, Fakultas Kedokteran, Universitas Tanjungpura, Pontianak \\ **Dosen Keperawatan, Fakultas Kedokteran, Universitas Tanjungpura, Pontianak \\ ***Dosen Keperawatan, Fakultas Kedokteran, Universitas Tanjungpura, Pontianak \\ Jl. Prof. Dr. H. Hadari Nawawi, Pontianak \\ Email: yudis1676@gmail.com
}

\begin{abstract}
ABSTRAK
Latar Belakang : ASI Eksklusif adalah bayi hanya diberi ASI saja selama 6 bulan, tanpa tambahan cairan lain, setelah 6 bulan baru mulai diberikan makanan pendamping ASI. Dukungan orang terdekat merupakan faktor penting dalam meningkatkan pemberian ASI eksklusif yaitu peran seorang suami. Dukungan suami dalam pemberian ASI eksklusif kepada isteri dapat meningkatkan pikiran positif istri, sehingga dapat meningkatkan hormon prolaktin dan refleks let dow.

Tujuan :Menganalisis hubungan dukungan suami dengan keberhasilan pemberian ASI eksklusif di wilayah kerja Pukesmas Pusat Damai Kabupaten Sanggau.

Metode: Penelitian kuantitatif menggunakan desain penelitian analitik observasional dengan menggunakan responden sebanyak 37 orang, dengan pengambilan sampel menggunakan teknik Snowball dengan syarat sampling spurposive sampling. Instrumen yang digunakan adalah lembar kuesioner. Uji yang digunakan pada penelitian ini yaitu uji Fisher.

Hasil : Hasil penelitian ini menunjukan sebanyak 11 ibu (29.7\%) mendapatkan dukungan suami dengan baik, sedangkan 21 ibu (56.8\%) mendapatkan dukungan suami cukup, dan 5 ibu (13.5\%) lainya mendapatkan dukungan suami kurang. Hasil uji statistik menunjukan tidak ada hubungan dukungan suami dengan keberhasilan pemberian ASI esklusif diwilayah kerja puskesmas pusat damai Kabupaten Sanggau dengan nilai p value $>0.05$ yaitu 0,540.

Kesimpulan : Tidak ada hubungan dukungan suami dengan keberhasilan pemberian ASI esklusif diwilayah kerja puskesmas pusat damai Kabupaten Sanggau, karena terdapat faktor - faktor yang mempengaruhi pemberian ASI eksklusif seperti, pengetahuan ibu, motivasi ibu, budaya, kesehatan ibu dan anak, psikologis ibu, dan peran petugas kesehatan.
\end{abstract}

Kata Kunci : Dukungan suami, Keberhasilan ASI eksklusif 


\begin{abstract}
Background: Exclusive breastfeeding is only babies fed on breast milk for 6 months, without the addition of other fluids, after 6 months of breastfeeding complementary feeding is only begin. Support of the closest person is an important factor in increasing exclusive breastfeeding, that is the role of a husband. Husband's support in giving exclusive breastfeeding to his wife can increase his wife's positive thoughts, so that it can increase the hormone prolactin and reflexes let dow.

Purpose: To analyze the relationship between husband's support and the success of exclusive breastfeeding in the Sanggau District Pusat Damai Community Service work area.

Method: Quantitative research used observational analytic research design using 37 respondents, with sampling using the Snowball technique with spurposive sampling sampling requirements. The instrument used was a questionnaire sheet. The test used in this study is the Fisher test.

Results: The results of this study showed that 11 mothers (29.7\%) received good husband support, while 21 mothers (56.8\%) received adequate support, and 5 mothers $(13.5 \%)$ received less husband support. The results of the statistical tests showed that there was no relationship between husband's support and the success of exclusive breastfeeding in the work area of the Pusat Damai health center in Sanggau District with a p value>0.05, which was 0.540.

Conclusion: There is no relationship between husband's support and the success of exclusive breastfeeding in the work area of the peaceful center health center of Sanggau Regency, because there are factors that influence exclusive breastfeeding such as mother's knowledge, mother's motivation, culture, maternal and child health, maternal psychology, and role health workers.
\end{abstract}

Keywords: Husband's support, Success of exclusive breastfeeding

\title{
PENDAHULUAN
}

Air Susu Ibu (ASI) sebagai makanan terbaik untuk bayi merupakan pemberian Tuhan yang tidak dapat ditiru oleh para ahli makanan dimanapun. ASI merupakan nutrisi alamiah terbaik bagi bayi karena mengandung kebutuhan energi dan zat yang dibutuhkan selama 6 bulan pertama kehidupan bayi. ${ }^{1}$ Menurut data WHO (2016), cakupan ASI eksklusif di seluruh dunia hanya sekitar $36 \%$ selama periode 2007-2014. ${ }^{2}$ Sedangkan pemberian ASI eksklusif di Indonesia menurut Data dan Informasi Profil Kesehatan Indonesia tahun 2017 termasuk dalam kategori rendah yaitu $35,73 \%$ bayi yang mendapatkan ASI Eksklusif sampai 6 bulan. Dengan Provinsi terendah memberikan ASI Eksklusif adalah Sumatera Utara $(10,73 \%)$, dan tertinggi Nusa Tenggara Barat $(75,42 \%){ }^{3}$ Menurut Data Dinas Kesehatan Provinsi Kalimantan Barat tahun 2018 cakupan ASI eksklusif di Kalimantan Barat mencapai $60,41 \%$, sehingga belum mencapai target ASI eksklusif yang telah ditentukan yaitu sebesar $80 \%$. Berdasarkan profil kesehatan 
kabupaten sanggau tahun 2017 bayi berumur 0-6 bulan yang mendapatkan ASI eksklusif hanya $1.755(19,70 \%)$ dari total jumlah bayi sebanyak 8.908 bayi. Dari hasil pengambilan data awal yang dilakukan oleh peneliti data di bulan januari tahun 2019 di Puskesmas Pusat Damai Kabupaten Sanggau, data ibu yang memberikan ASI ekslusif sebanyak 9 orang $(20,45 \%)$, dari 44 bayi yang lahir hidup. Banyaknya bayi yang tidak mendapatkan ASI eksklusif di Indonesia disebabkan oleh berbagai faktor seperti umur ibu, pengetahuan ibu, petugas kesehatan, kebiasaan yang keliru, pekerjaan ibu, dan dukungan keluarga. Dukungan orang terdekat juga merupakan faktor penting dalam meningkatkan pemberian ASI eksklusif ibu terhadap bayi yaitu peran seorang suami. Dukungan suami dalam pemberian ASI eksklusif kepada isteri dapat meningkatkan pikiran positif istri, isteri menjadi lebih berhatihati dalam memberikan makanan tambahan, selain itu dapat juga meningkatkan hormon prolaktin dan refleks let down. ${ }^{4}$ Namun pada kenyataannya, dukungan suami dalam praktek pemberian ASI masih minim, salah satunya karena secara kultural ada pembagian peran, dimana suami berperan sebagai pencari nafkah dan urusan rumah tangga semuanya diurusi oleh istri. ${ }^{5}$ Tingkat keberhasilan pemberian ASI eksklusif bisa berhasil sukses dengan adanya dorongan suami kepada ibu menyusui memberikan ASI pada bayi. Menurut Cholil et al dalam Bobak (2004) ada beberapa faktor yang mempengaruhi dukungan suami antara lain pedidikan suami dan pendapatan suami. Seorang suami yang mengerti dan memahami bagaimana manfaat ASI pasti akan selalu membantu ibu mengurus bayi, termasuk menggantikan popok, memandikan bayi, memberikan pijatan pada bayi, menyediakan anggaran ekstra, membantu mengatasi masalah dalam pemberian ASI, dan selalu manjaga romantisme dengan istri. Sementara ibu, berusaha fokus meningkatkan kualitas ASI, dengan mengonsumsi makanan bergizi seimbang dan melakukan pola hidup sehat. ${ }^{6}$ Memberi ASI eksklusif hingga bayi berusia 6 bulan sangat bermanfaat karena ASI eksklusif memiliki banyak maanfaat seperti untuk membantu pertumbuhan otak, meningkatkan penglihatan, dan meningkatkan kecerdasan. ASI eksklusif juga mampu mengurangi resiko terjadinya penyakit kronik yang mungkin terjadi pada masa remaja dan dewasa, seperti diabetes type I dan type II, obesitas, penyakit jantung, dan penyakit Crohn. Manfaat ASI eksklusif bukan hanya bermanfaat bagi bayi saja namun bagi ibu yang menyusui juga memiliki manfaat dari ASI eksklusif. ASI eksklusif dapat mengurangi resiko terjadinya perdarahan setelah persalinan, kanker payudara dan kanker ovarium. ${ }^{7}$ Berdasarkan studi pendahuluan yang dilakukan peneliti di Puskesmas Pusat Damai ASI merupakan program utama puskesmas. Petugas puskesmas selalu mendorong ibu untuk memberikan ASI eksklusif pada bayi. Bentuk dorongan yang diberikan berupa penyuluhan ketika antenatal care (ANC), berupa manfaat ASI eksklusif, cara dan tehnik menyusui yang benar dan ketika posyandu petugas puskesmas selalu mengingatkan akan pentingnya memberikan ASI eksklsuif untuk bayi. Dari hasil wawancara yang dilakukan kepada 6 ibu yang memiliki bayi 0-6 bulan, hanya 2 ibu yang berhasi memberikan ASI eksklusif, sedang kan 4 ibu lainya tidak memberikan ASI eksklusif pada bayinya karena berbagai faktor seperti ibu sibuk mengurus pekerjaan rumah tangga, dan ASI kurang. Satu dari 2 ibu yang berhasil memberikan ASI eksklusif mengatakan bahwa suaminya selalu membantu ibu dalam melakukan pekerjaan rumah sehingga ibu merasa terbantu dan fokus dalam memberikan ASI pada bayi dan suami sering menemani ibu ketika menyusui bayi pada saat tengah malam. Sedangkan ibu lainya mengatakan bahwa suami jarang memberikan bantuan dikarenakan suami yang sibuk bekerja. 
Berdasarkan fenomena yang telah dipaparkan diatas, maka peneliti tertarik untuk mengkaji lebih dalam hubungan dukungan suami dengan keberhasilan pemberian ASI ekslusif di wilayah kerja Pukesmas Pusat Damai kabupaten sanggau.

\section{BAHAN DAN METODE}

Jenis penelitian ini adalah penelitian kuantitatif menggunakan desain penelitian analitik observasional Penelitian ini dilaksanakan di wilayah kerja Puskesmas Pusat Damai Kabupaten Sanggau dan waktu pengumpulan data dimulai pada tanggal 25 - 28 Juni 2019. Jumlah sampel pada penelitian ini sebanyak 37 responden. Teknik yang digunakan untuk pengambilan sampel pada penelitian ini adalah teknik Snowball dengan syarat sampling spurposive sampling. Instrumen yang digunakan pada penelitian ini yaitu lembar kuesioner dengan skala Likert dan alat tulis. Analisis data pada penelitian ini menggunakan analisis statistik komputer. Setelah data terkumpul kemudian dilakukan pengolahan data dengan menggunakan frekuensi untuk analisis univariat, dan analisis bivariat menggunakan uji Fisher untuk melihat hubungan dua variabel.

\section{HASIL}

1. Analisis Univariat

Tabel 1. Distribusi frekuensi berdasarkan umur responden

\begin{tabular}{lll}
\hline $\begin{array}{l}\text { Rentang } \\
\text { Usia }\end{array}$ & $\begin{array}{c}\text { Frekuensi } \\
(f)\end{array}$ & $\begin{array}{l}\text { Persentase } \\
(\%)\end{array}$ \\
\hline $17-25$ & 17 & 45,9 \\
$26-35$ & 11 & 29,7 \\
$36-45$ & 8 & 21,6 \\
$46-55$ & 1 & 2,8 \\
\hline Total & 37 & 100 \\
\hline
\end{tabular}

Tabel 2. Distribusi frekuensi berdasarkan Tingkat pendidikan istri

\begin{tabular}{lll}
\hline Tingkat & Frekuensi & Persentase \\
Pendidikan Ibu & $(f)$ & $(\%)$
\end{tabular}

\begin{tabular}{lll}
\hline SD & 13 & 35.1 \\
SMP & 5 & 13.5 \\
SMA & 17 & 45.9 \\
Diploma/Sarjana & 2 & 5.5 \\
\hline Total & 37 & 100 \\
\hline
\end{tabular}

Tabel 3. Distribusi frekuensi berdasarkan Tingkat pendidikan suami

\begin{tabular}{lll}
\hline $\begin{array}{l}\text { Tingkat } \\
\text { Pendidikan Suami }\end{array}$ & $\begin{array}{l}\text { Frekuensi } \\
(f)\end{array}$ & $\begin{array}{l}\text { Persentase } \\
(\%)\end{array}$ \\
\hline SD & 9 & 24.3 \\
SMP & 8 & 21.6 \\
SMA & 19 & 51.4 \\
Diploma/Sarjana & 1 & 2.7 \\
\hline Total & 37 & 100 \\
\hline
\end{tabular}

Tabel 4. Distribusi frekuensi berdasarkan Pekerjaan ibu

\begin{tabular}{lll}
\hline Pekerjaan Ibu & $\begin{array}{l}\text { Frekuensi } \\
(f)\end{array}$ & $\begin{array}{l}\text { Persentase } \\
(\%)\end{array}$ \\
\hline Tidak bekerja & 29 & 78.4 \\
PNS & 0 & 0 \\
Wiraswasta & 1 & 2.7 \\
Pegawai swasta & 0 & 0 \\
Lain - lain & 7 & 18.9 \\
\hline Total & 37 & 100 \\
\hline
\end{tabular}

Tabel 5. Distribusi Frekuensi Dukungan Suami

\begin{tabular}{lll}
\hline Dukungan Suami & $\begin{array}{l}\text { Frekuensi } \\
(f)\end{array}$ & $\begin{array}{l}\text { Persentase } \\
(\%)\end{array}$ \\
\hline Baik & 11 & 29.7 \\
Cukup & 21 & 56.8 \\
Kurang & 5 & 13.5 \\
\hline Total & 37 & 100 \\
\hline
\end{tabular}

Tabel 6. Distribusi Frekuensi berdasarkan Keberhasilan Pemberian ASI Eksklusif

\begin{tabular}{lll}
\hline ASI Eksklusif & $\begin{array}{l}\text { Frekuensi } \\
(f)\end{array}$ & $\begin{array}{l}\text { Persentase } \\
(\%)\end{array}$ \\
\hline Tidak Berhasil & 34 & 91.9 \\
Berhasil & 3 & 8.1 \\
\hline Total & 37 & 100 \\
\hline
\end{tabular}

Sumber: Data Primer (2019)

Hasil analisis pada tabel di atas dapat disimpulkan bahwa sebagian besar kategori usia responden yaitu rentang usia remaja akhir yaitu (17-25 tahun) sebanyak $45,9 \%$. Kategori pendidikan ibu dan suami sebagian besar berpendidikan SMA sebanyak 17 (45.9\%) dan 19 (51.4\%). 
Tabel 4.4 memperlihatkan bahwa dari 37 Ibu , 29 ibu (78.4\%) diantaranya tidak bekerjaan, sedangkan ibu lainnya memiliki pekerjaan sebagai wiraswasta, dan lainlain seperti petani. Berdasarkan distribusi frekuensi dukungan suami menunjukkan bahwa dukungan suami dengan pemberian ASI eksklusif termasuk dalam kategori kurang sebanyak 33 responden $(54,1 \%)$. Berdasarkan distribusi frekuensi kemauan ibu menunjukkan bahwa bahwa kemauan ibu dalam pemberian ASI eksklusif termasuk dalam kategori tidak memberikan ASI eksklusif sebanyak 53 responden $(86,9 \%)$.

\section{Analisis Bivariat}

Tabel 7. Hubungan Dukungan Suami Terhadap Keberhasilan Pemberian ASI Eksklusif

\begin{tabular}{|c|c|c|c|c|}
\hline \multirow{2}{*}{$\begin{array}{l}\text { Dukungan } \\
\text { Suami }\end{array}$} & \multicolumn{2}{|c|}{$\begin{array}{l}\text { Keberhasilan } \\
\text { eksklusif }\end{array}$} & \multirow[b]{2}{*}{$\begin{array}{l}\text { Total } \\
f(\%)\end{array}$} & \multirow{2}{*}{$\begin{array}{l}\mathrm{P} \\
\text { value }\end{array}$} \\
\hline & $\begin{array}{l}\text { Berhasil } \\
f(\%)\end{array}$ & $\begin{array}{l}\text { Tidak } \\
\text { berhasil } \\
f(\%)\end{array}$ & & \\
\hline Baik & $0(0)$ & $11(100)$ & $11(100)$ & \multirow{4}{*}{0.540} \\
\hline Cukup & $2(9.5)$ & $19(90.5)$ & $21(100)$ & \\
\hline Kurang & $1(20)$ & $4(80)$ & $5(100)$ & \\
\hline Total & $3(8.1)$ & 34 (91.9) & $37(100)$ & \\
\hline
\end{tabular}

Sumber: Penggabungan sel dan Uji Fisher (2019)

Tabel 4 diatas didapatkan hasil bahwa tidak ada ibu yang berhasil memberikan ASI eksklusif pada anaknya dan mendapatkan dukungan suami yang baik dan ibu yang berhasil memberikan ASI eksklusif dan mendapakan dukungan suami yang cukup sebanyak 2 orang (9.5\%), sedangkan ibu yang berhasil memberikan ASI eksklusif dan mendapatkan dukungan suami yang kurang sebanyak 1 orang (20\%) dan ibu yang tidak berhasil memberikan ASI eksklusif dan mendapakan dukungan suami yang baik sebanyak 11 orang (100\%), sedangkan ibu yang tidak berhasil memberikan ASI eksklusif dan mendapatkan dukungan suami yang cukup sebanyak 19 orang (90.5\%). Hasil uji analisis Fisher menunjukan nilai $\mathrm{p}$ value $=$ 0.540 sehingga Ha ditolak $(\mathrm{P}>0.05)$. Hal ini menunjukan bahwa tidak ada hubungan antara variabel dukungan suami dengan variabel keberhasilan ASI eksklusif.

\section{PEMBAHASAN \\ Karakteristik Responden Berdasarkan Usia}

Hasil penelitian yang telah dilakukan oleh peneliti pada 37 responden di wilayah kerja Puskesmas Pusat Damai Kabupaten Sanggau didapatkan bahwa usia ibu terbanyak adalah masuk dalam golongan masa remaja akhir dengan jumlah $17 \mathrm{ibu}$ $(45,9 \%)$. Faktor umur berpengaruh dalam perubahan sikap, bertambahnya umur dapat mempengaruhi pembentukan dan perubahan sikap melalui proses yang disebut diferensiasi. Diferensiasi merupakan cara pembentukan sikap karena sudah dimilikinya pengetahuan, pengalaman, intelegensi, dan bertambahnya umur. $^{8}$ Umur merupakan variabel penting dalam siklus kehidupan manusia. Dikatakan bahwa umur terbaik untuk reproduktif sehat adalah rentang 20 - 35 tahun. Pada usia ini dianggap sebagai periode emas untuk bereproduksi karena fungsi-fungsi organ reproduksi dinilai sudah matang sehingga siap untuk hamil, melahirkan dan menyusui. ${ }^{9}$ Umur dapat melatar belakangi seseorang untuk melakukan suatu perilaku, karena setiap kelompok umur memiliki pandangan yang berbeda. Ibu yang berada pada masa dewasa akan lebih mengerti dan paham terhadap suatu hal dibandingkan dengan ibu yang belum memasuki usia dewasa. ${ }^{10}$

\section{Karakteristik Responden Berdasarkan Pendidikan}

Hasil penelitian ini berdasarkan karakteristik pendidikan responden menunjukkan bahwa tingkat pendidikan responden yang diteliti bermacam-macam, sebagian besar subjek penelitian adalah responden yang berpendidikan SMA. Semakin tinggi tingkat pendidikan seseorang, maka semakin mudah pula 
seseorang untuk menerima informasi. Informasi yang didapat seseorang nantinya akan mempengaruhi pengetahuan. ${ }^{10}$ Hasil penelitian ini sejalan dengan Anggrita (2009), yang mengatakan tidak ada hubungan yang bermakna antara tingkat pendidikan ibu menyusui dengan pemberian ASI eksklusif. ${ }^{11}$ Penelitian ini didukung oleh Elmiyasna (2009) yang menyatakan bahwa tidak ada kaitan antara pendidikan ibu dengan pemberian ASI eksklusif. Hal itu dikarenakan pendidikan yang diterima seseorang akan mempengaruhi pengetahuan, karena pendidikan seseorang tidak hanya dipengaruhi oleh pendidikan formal tetapi juga pendidikan yang dipengaruhi oleh pendidikan informal yaitu pengalaman dari ibu itu sendiri atau mendapatkan pengalaman atau cerita dari orang lain. ${ }^{12}$ Hasil berbeda dengan penelitian yang dilakukan oleh Setia (2018) yang mengatakan bahwa ada hubungan antara pendidikan ibu dengan pemberian ASI Eksklusif di Wilayah Kerja Puskesmas Hinai kiri. Tingkat pendidikan ibu dan pengetahuan ibu merupakan faktor yang penting untuk mendukung keberhasilan ASI eksklusif pada bayi, karena semakin tinggi tingkat pendidikan seseorang semakin mudah menerima informasi sehingga semakin banyak pengetahuan yang dimiliki ${ }^{13}$. Sebaliknya pendidikan yang kurang akan menghambat perkembangan sikap seseorang terhadap nilai-nilai yang diperkenalkan ${ }^{14}$.

\section{Karakteristik Responden Berdasarkan Pekerjaan Ibu}

Hasil dari penelitian menunjukkan bahwa mayoritas ibu sebanyak 29 orang (78.4\%) tidak bekerja. Beberapa faktor yang menyebabkan bayi tidak diberikan ASI dengan baik. Faktor tersebut adalah faktor karakteristik ibu, faktor bayi, lingkungan, dukungan keluarga, pendidikan kesehatan, sosial ekonomi dan budaya. ${ }^{15} \mathrm{Di}$ daerah perkotaan dimana relatif lebih banyak ibu yang bekerja untuk mencari nafkah mengakibatkan ibu tidak dapat menyusui bayinya dengan baik dan teratur. Hal ini menjadi signifikan karena situasi tempat kerja belum mendukung praktik pemberian ASI, misalnya tidak tersedianya tempat memerah dan menyimpan ASI, belum banyak tersedia atau tidak adanya tempat penitipan bayi agar ibu pekerja dapat menyusui bayinya pada saat tertentu. ${ }^{16}$ Elinofia (2011) mengatakan Kelompok ibu yang bekerja mengalami dilema dalam memberikan ASI meskipun mereka tahu manfaat dan keunggulan ASI namun sulit untuk mempraktekkannya. Dengan bekerja ibu tidak dapat berhubungan penuh dengan bayinya, akibatnya ibu cenderung memberikan susu formula dan diberikan melalui botol, menyebabkan frekuensi menyusui akan berkurang dan produksi ASI akan menurun. Keadaan ini menyebabkan ibu menghentikan pemberian ASI. ${ }^{17}$

\section{Gambaran Dukungan Suami Dengan Keberhasilan ASI Eksklusif}

Hasil penelitian menunjukkan bahwa tidak ada ibu yang berhasil memberikan ASI eksklusif pada anaknya dan mendapatkan dukungan suami yang baik dan ibu yang berhasil memberikan ASI eksklusif dan mendapatkan dukungan suami yang cukup sebanyak 2 orang $(9.5 \%)$, sedangkan ibu yang berhasil memberikan ASI eksklusif dan mendapatkan dukungan suami yang sebanyak 1 orang (20\%). Ibu yang tidak berhasil memberikan ASI eksklusif dan mendapakan dukungan suami yang baik sebanyak 11 orang (100\%), sedangkan ibu yang tidak berhasil memberikan ASI eksklusif dan mendapatkan dukungan suami yang cukup sebanyak 19 orang (90.5\%). Dukungan suami adalah salah satu bentuk interaksi yang didalamnya terdapat hubungan yang saling memberi dan menerima bantuan yang bersifat nyata yang dilakukan oleh suami terhadap istrinya. ${ }^{18}$ Dukungan suami merupakan salah satu faktor yang mempengaruhi 
sikap ibu dalam pemberian ASI eksklusif. Dukungan suami terdiri dari empat jenis yaitu dukungan informasional, dukungan penilaian, dukungan fisik, dan dukungan emosional. ${ }^{19}$ Hasil penelitian menunjukkan bahwa tidak semua ibu memiliki dukungan suami yang baik. Hasil tersebut dapat disebabkan karena dukungan suami dapat dipengaruhi oleh beberapa hal diantaranya faktor internal dan faktor eksternal. Faktor internal yang mempengaruhi dukungan suami adalah faktor emosi dan pendidikan serta tingkat pengetahuan. Faktor internal berasal dari dalam diri seseorang, hal ini jelas dapat menyebabkan dukungan suami yang diperoleh ibu berbeda antara ibu yang satu dengan ibu yang lainnya karena tiap individu memiliki emosi, pendidikan, dan tingkat pengetahuan yang berbeda. Faktor internal ini terkait dengan dukungan informasional, dukungan penilaian, dukungan fisik, dan dukungan emosional. Faktor eksternal yang mempengaruhi dukungan suami adalah latar belakang budaya dan struktur keluarga. Faktor ini memiliki pengaruh lebih kecil dibandingkan dengan faktor internal. Latar belakang budaya pada ibu menyusui eksklusif yang memiliki bayi usia 0-6 bulan hampir sama karena mereka berada dalam satu wilayah yaitu di wilayah kerja Puskesmas Arjasa Kabupaten Jember. ${ }^{20}$

\section{Gambaran Keberhasilan Pemberian ASI Eksklusif Pada Bayi usia 0-6 bulan}

ASI eksklusif adalah pemberian air susu ibu saja kepada bayi selama enam bulan pertama kehidupan bayi tanpa memberikan makanan atau cairan lain. Hasil penelitian ini menunjukan bahwa terdapat $3 \mathrm{ibu}(8.1 \%)$ yang berhasil memberikan ASI eksklusif sampai usia 6 bulan dan sebanyak 34 ibu (91.9\%) tidak berhasil memberikan ASI eksklusif sampai usia 6 bulan diwilayah kerja puskesmas pusat damai. Terdapat bebrapa faktor yang mempengaruhi ibu tidak mau memberikan ASI sampai usia 6 bulan antara lain yaitu ASI tidak cukup atau tidak keluar, ibu menganggap susu formula lebih praktis, takut badan tambah gemuk. Masalah badan takut gemuk karena dengan menyusi ibu akan lebih banyak makan sehingga ibupun berfikir dengan makan banyak akan membuat tubuhnya tidak bisa ideal lagi sehingga daya tarik berkurang tanpa memperhatikan kebutuhan nutrisi sang bayi, kurangnya pemahaman ibu mengenai ASI eksklusif, dan terdapatnya mitos-mitos yang beredar di masyarakat, serta rasa takut ibu terhadap ASI yang dihasilkannya kurang.

\section{Hubungan Dukungan Suami Dengan Keberhasilan Pemberian ASI Eksklusif Pada Ibu}

Setelah melakukan penelitian di Wilayah Kerja Puskesmas Pusat Damai Kabupaten Sanggau Tahun 2019 pada bulan Juni 2019, dengan jumlah 37 responden didapatkan hasil penelitian mengenai Hubungan dukungan suami dengan keberhasilan pemberian ASI esklusif di Wilayah Kerja Puskesmas Pusat Damai bahwa tidak terdapat responden yang mendapatkan dukungan suami yang baik dan berhasil memberikan ASI eksklusif. Setelah dilakukan perhitungan uji statistic, didapatkan hasil bahwa tidak ada hubungan dukungan suami dengan keberhasilan pemberian ASI esklusif nilai $\mathrm{P}>0.05$ yaitu 0.540 . Hal ini diartikan bahwa tidak ada hubungan dukungan suami dengan keberhasilan pemberian ASI esklusif di Wilayah Kerja Puskesmas Pusat Damai. Perbedaan hasil penelitian yang dilakukan Priscilla dengan hasil penelitian yang dilakukan oleh peneliti dapat disebabkan oleh beberapa faktor lain yang dalam penelitian ini peneliti tidak lakukan kontrol seperti pengetahuan Ibu, pengetahuan yang dimiliki ibu hamil mengenai manajemen laktasi harus baik pada tiap tahapnya. Dengan pengetahuan yang baik maka akan menimbulkan sikap yang baik sehingga pada akhirnya manajemen laktasi dapat terlaksana dengan baik pula. Banyak ibu yang masih belum paham mengenai proses menyusui dan manfaatnya. Pengetahuan yang cukup akan 
memperbesar kemungkinan sukses dalam pemberian ASI eksklusif pada bayi. ${ }^{21}$ Motivasi ibu juga mempengaruhi dalam pemberian ASI eksklusif Motivasi merupakan satu bentuk dorongan seseorang untuk melakukan sesuatu. Motivasi membantu seseorang membentuk tingkah lakunya dan membantu mencapai kepuasan setelah segala keperluan dan kehendak dapat dipenuhi. Bahiyatun (2009), agar menyusui lebih berhasil, seorang ibu memerlukan rasa percaya diri, yaitu ibu harus yakin bahwa ibu dapat menyusui dan ASI adalah yang terbaik untuk bayinya. Ibu harus yakin bahwa ASI akan mencukupi kebutuhan bayinya, terutama pada awal bulan setelah lahir. ${ }^{22}$ Fasilitas pelayanan kesehatan tempat melahirkan memberikan pengaruh terhadap pemberian ASI eksklusif pada bayi karena merupakan titik awal bagi ibu untuk memilih tetap memberikan ASI eksklusif atau memberikan susu formula yang diberikan oleh petugas kesehatan maupun non kesehatan sebelum ASI keluar. Banyak rumah sakit, puskesmas, klinik, dan rumah bersalin yang belum merawat bayi baru lahir berdekatan dengan ibunya, sehingga ibu tidak dapat menyusui bayinya sedini mungkin dan kapan saja dibutuhkan. ${ }^{23}$ Peranan petugas kesehatan juga sangat penting dalam memberikan ASI eksklusif Ibu umumnya mau patuh, dan menuruti nasehat petugas kesehatan, oleh karena itu petugas kesehatan diharapkan untuk memberikan informasi tentang waktu yang tepat untuk memberikan ASI eksklusif. Manfaat ASI eksklusif dapat meningkatkan daya tahan tubuh dan resiko tidak memberikan ASI eksklusif pada bayi. ${ }^{24}$ Dukungan keluarga dari keluarga dekat, terutama wanita seperti ibu, ibu mertua, kakak wanita, atau teman wanita lain yang telah berpengalaman dan berhasil dalam menyusui sangat diperlukan. Perlunya dukungan dari suami yang mengerti bahwa ASI adalah makanan yang baik untuk bayinya merupakan pendukung yang baik demi keberhasilan menyusui. ${ }^{22}$ Faktor
Kebiasaan atau kebudayaan juga merupakan faktor yang mempengaruhi ibu dalam pemeberian ASI eksklusif. Kebiasaan atau kebudayaan merupakan seperangkat kepercayaan, nilai-nilai dan cara perilaku yang dipelajari secara umum dan dimiliki bersama oleh warga di masyarakat. Kebiasaan yang keliru adalah pemberian prelaktal madu dan susu formula menggunakan dot kepada bayi baru lahir, pemberian MP-ASI yang terlalu dini dan kebiasaan pembuangan kolostrum. Kebiasaan lain yang keliru antara lain memberi air putih dan cairan lain seperti teh, air manis, dan jus kepada bayi menyusui dalam bulan-bulan pertama. ${ }^{25}$ Menyusui memerlukan kondisi emosional yang stabil, mengingat faktor psikologis ibu sangat memengaruhi produksi ASI. Menurut Roesli (2007), dari semua dukungan bagi ibu menyusui dukungan suami paling berarti bagi ibu. Suami dapat berperan aktif dalam keberhasilan ASI eksklusif karena suami akan turut menentukan kelancaran refleks pengeluaran ASI yang sangat dipengaruhi oleh keadaan emosi atau perasaan ibu. Dukungan suami merupakan salah satu faktor penting dalam memicu refl eks oksitosin sehingga produksi ASI meningkat. ${ }^{26}$

\section{SIMPULAN}

Berdasarkan hasil penelitian dan pembahasan hubungan antara dukungan suami dengan keberhasilan pemberian ASI eksklusif diwilayah kerja puskesmas pusat damai maka dapat disimpulkan bahwa :

a. Krakteristik responden yang ada di diwilayah kerja puskesmas pusat damai berdasarkan katagori umur terbanyak adalah pada golongan masa remaja akhir dengan jumlah 17 responden. Pendidikan ibu terbanyak adalah SMA sebanyak 17 orang, pendidikan suami terbanyak adalah SMA Sebanyak 19 orang. Karakteristik responden berdasarkan 
pekerjaan ibu adalah 29 ibu diantaranya tidak bekerjaan.

b. Dukungan suami dalam pemberian ASI eksklusif diwilayah kerja puskesmas pusat damai sebanyak 11 ibu mendapatkan dukungan suami dengan baik, sedangkan 21 ibu mendapatkan dukungan sumai cukup, dan 5 ibu lainya mendapatkan dukungan suami kurang.

c. Keberhasilan ASI eksklusif diwilayah kerja puskesmas pusat damai sebanyak 34 responden tidak berhasil dalam memberikan ASI eksklusif, sedangkan 3 responden lainya berhasil memberikan ASI eksklusif.

d. Tidak ada hubungan dukungan suami dengan keberhasilan pemberian ASI esklusif diwilayah kerja puskesmas pusat damai Kabupaten Sanggau dengan nilai $\mathrm{P}>0.05$ yaitu 0,540

\section{SARAN}

Saran yang dapat diberikan terkait dengan hasil dan pembahasan penelitian ini adalah sebagai berikut:

\section{Bagi Institusi Pendidikan}

Hasil penelitian ini dapat digunakan sebagai evidence based bagi Fakultas Kedokteran Program Studi Keperawatan Universitas Tanjungpura tentang hubungan antara dukungan suami dengan keberhasilan pemberian ASI eksklusif.

\section{Bagi Lahan Penelitian}

Hasil dan pembahasan dari penelitian ini diharapkan dapat menjadi suatu referensi bagi mahasiswa keperawatan dalam Mengadakan penelitian lebih lanjut mengenai dukungan suami dengan keberhasilan pemberian ASI eksklusif.

\section{Bagi Tenaga Kesehatan}

Tenaga kesehatan seperti perawat, bidan, dokter, dan ahli gizi perlu meningkatkan promosi mengenai ASI eksklusif dan manfaat dari ASI eksklsuif kepada ibu dan suami. Sehingga keberhasilan pemberian ASI eksklusif dapat tercapai.

\section{Bagi Masyarakat}

Hasil dari penelitian ini memberikan saran pada masyarakat yaitu:

a. Berpartisipasi dan bekerjasama dengan petugas kesehatan dengan memberikan dukungan dan motivasi kepada ibu untuk memberikan ASI eksklusif kepada bayinya.

b. Bersikap terbuka dan bersedia menerima informasi dari petugas kesehatan terkait informasi mengenai program ASI eksklusif dan memnghilangkan budaya pemberian MP-ASI sebelum bayi berusia 6 bulan.

c. Anggota keluarga khususnya suami, agar ikut berpartisipasi dalam pemberian ASI eksklusif dengan cara memberikan dukungan (informasional, penilaian, fisik, dan emosional) selama ibu menyusui eksklusif sampai usia bayi 6 bulan.

\section{KEPUSTAKAAN}

1. Wulandari, S., \& Handayani, S. (2011). Asuhan Kebidanan Ibu Masa Nifas. Yogyakarta: Gosyen Publishing.

2. World Health Organization. 2016a. Breastfeeding: Only 1 in 5 Countries Fully Implement WHO's Infant Formula Code. Diakses: 10 Mei 2019. http://www.who.int/mediacentre/news /releases/2013/world_breastfeeding_w ek_20130730/en/

3. Sulistyoningsih, H. (2011). Gizi untuk Kesehatan Ibu dan Anak. Yogyakarta: Penerbit Buku Graha Ilmu.

4. Dharma KK. Metodologi Penelitian Keperawatan: Panduan Melaksanakan dan Menerapkan Hasil Penelitian. Jakarta: Trans Info Media,2017.

5. Dinas Kesehatan Kabupaten Kubu Raya. Profil Dinas Kesehatan Provinsi Kalbar: Kubu Raya,2017.

6. Malau, A. (2010). Hubungan Dukungan Suami dan Kemauan Ibu Memberikan ASI Eksklusif di Puskesmas Teladan Medan. Diambil 
dari(http://rusmanefendi.files.wordpre ss.com/2010/03/s-hubungan-

dukungan-suami-dan kemauan-ibumemberikan-asi-eksklusif.pdf

7. Bobak. (2004). Buku Ajar Keperawatan Maternitas. Edisi 4. Jakarta: EGC.

8. WHO. Acceptable medical reasons for use of breast milk substitutes. World Health Organization. Geneva. 2009

9. Sunaryo. 2004. Psikologi Untuk Keperawatan. Jakarta: EGC.

10. Hanulan Septiani, Artha Budi, Karbito. 2017. Faktor-Faktor yang Berhubungan dengan Pemberian ASI Eksklusif Oleh Ibu Menyusui yang Bekerja Sebagai Tenaga Kesehatan. Jurnal Aisyah: Jurnal Ilmu Kesehatan. Vol. 2, No.2

11. Kurniawati, D. 2014. Faktor Determinan yang Mempengaruhi Kegagalan Pemberian ASI Eksklusif pada Bayi Usia 6-12 bulan di Kelurahan Mulyorejo Wilayah Kerja Puskesmas Mulyorejo Surabaya.

12. Anggrita, Kiki. 2009. Hubungan Karakteristik Ibu Menyusui Terhadap Pemberian ASI Eksklusif Di Wilayah Kerja Puskesmas Medan Amplas Tahun 2009. Tidak diterbitkan. Skripsi. Medan: Fakultas kedokteran Universitas Sumatera Utara.

13. Elmiyasna. 2009. Kajian Pemberian ASI Eksklusif Kaitannya Dengan Pendidikan Dan Pekerjaan Ibu Menyusui Di Puskesmas Nanggolo Padang. Artikel Penelitian. Padang: STIKES Mercu Bakti Jaya.

14. Fikawati, S., dan Syafiq, A.2012. Kajian Implementasi dan Kebijakan Air Susu Ibu Eksklusif dan Inisiasi Menyusui Dini Di Indonesia. Jakarta:EGC

15. Setia Sihombing. 2018. Hubungan Pekerjaan. Dan Pendidikan Ibu Dengan pemberian ASI Eksklusif Di wilayah Kerja Puskesmas Hinai Kiri . Jurnal Bidan Midwife Journal. Volume 5 No. 01
16. Budiharjo.2013. Panduan Ibu Cerdas (ASI dan Tumbuh Kembang Bayi). Yogyakarta:Medis Presindo

17. Elinofia. Hubungan Pendidikan, Pengetahuan, Pekerjaan dan Dukungan Keluarga dengan Pemberian ASI Eksklusif di Puskesmas Sawah Lebar. Bengkulu: 2011.

18. Sari, Reni Restu. 2011. Hubungan karakteristik, Pengetahuan, Sikap Dan Dukungan Ayah Terhadap Pemberian ASI Eksklusif Di Wilayah Kerja Puskesmas Takang Kabupaten Solok Tahun 2011 (di akses dari http://lib.ui.ac.id di unduh pada 29 juni 2019)

19. Februhartanty, Judhiastuty. (2008). Peran Ayah dalam Optimalisasi Praktek Pemberian ASI: Sebuah Studi di Daerah Urban Jakarta.

20. Yanita Trisetyaningsih, Afi Lutfiyati, Anto Pamungkas Kurniawan. 2017. Dukungan keluarga Berperan Penting dalam Pencapaian Peran Ibu Primipara. Jurnal Kesehatan "Samodra Ilmu". Vol. 08 No. 01.

21. Prasetyono, Juli D. 2010. Hubungan Dukungan Keluarga Dengan Kepatuhan Berobat Pasien TB Paru Di Wilayah Kerja Puskesmas Sumberjambe Kabupaten Jember. Skripsi. Jember: Program Studi Ilmu Keperawatan Universitas Jember.

22. Bahiyatun. (2009). Buku Ajar Asuhan Kebidanan Nifas Normal. Jakarta: EGC.

23. Damayanti, Diana. 2010. Asyiknya Minum ASI. Jakarta: PT. Gramedia Pustaka Utama

24. Afifah, D.N. (2007). Faktor yang Berperan dalam Kegagalan Praktik Pemberian ASI Eksklusif. Semarang: [serial on line] Artikel Penelitian. http://eprints.undip.ac.id/1034/1/ARTI KEL_ASI.pdf

25. Roesli U. (2008). Inisiasi Menyusui Dini plus ASI Eksklusif. Jakarta: Pustaka Bunda. Hal 3-7. 
26. Rohani. (2007). Pengaruh Karakteristik Ibu Menyusui Terhadap Pemberian ASI Eksklusif Di Wilayah Kerja Puskesmas Teluk Kecamatan Secanggang Kabupaten Langkat Tahun 2007, (Online), diakses tanggal 12 februari 2019, (http://library.usu.ac.id) 